\title{
Crystal gazing: biotech's financial outlook
}

\author{
Eric Schmidt \& David J Strupp
}

A leading biotech analyst and an investment banker give their perspectives on the future of biotech.

The biotech industry has made huge strides over the past ten years. Today's industry, which features over 180 approved products, revenues of approximately $\$ 50$ billion and a market value well over $\$ 300$ billion, is barely recognizable as the same industry that in 1996 featured just 34 approved products, revenues of $\$ 9$ billion and a market value of $\$ 52$ billion. But is the future as rosy?

It is startling to think that over the past ten years Amgen's (Thousand Oaks, CA) market value has increased nearly tenfold and Genentech's (S. San Francisco, CA), nearly 20fold. Today, these firms are significantly larger than the pharma giants Merck (Whitehouse Station, NJ), Eli Lily (Indianapolis, IN), Abbott (Deerfield, IL), Wyeth (Madison, NJ), Bristol Myers (Princeton, NJ) and Schering Plough (Kenilworth, NJ). Few would have predicted that by 2006, biotech drugs would dominate the commercial landscape in important therapeutic areas like cancer, inflammation and HIV. Whereas ten years ago investors questioned whether the biotech industry was even sustainable, today the key question is, Just how much success will biotech enjoy?

In business, success breeds challenges, and the biotech industry's ability to build on its accomplishments over the next ten years is far from assured. As it matures, the industry will have to deal with a host of new issues reserved for larger, more mature and profitable industries. The rules of the game are likely to change for investors, as well, in a number of significant ways.

Eric Schmidt is Senior Analyst at Cowen \& Co. e-mail:Eric.Schmidt@cowen.com

\section{Valuations}

In the past, investors awarded nearly every profitable biotech company with a premium multiple on earnings. Companies that achieved profitability were in great demand and conventional wisdom was that each deserved to trade at a premium reflective of its superior long-term growth characteristics and renewable pipeline.

In reality, biotech is a loosely defined group of tools, services, specialty pharmaceutical and drug discovery companies with vastly different business models, customer bases and growth potential. Investors will begin to deal with the industry accordingly, in an arguably more rational manner.

Certain business models, such as the in-licensing-based approach that is so popular today, might be associated with lower long-term rewards to investors. In addition, investors have learned that one success in drug development rarely ensures similar success in the future. In many respects, Amgen and Genentech are anomalies. We believe investors will begin to look at earnings and a variety of other financial metrics (cash flow, growth potential, return on invested capital, asset value, R\&D investment) when assigning a valuation to an individual 'biotech' company.

This changing mind-set in the analyst community means that biotechs in the future can expect to be judged much more critically than they have been in the past.

\section{The waning mystique of collaborations}

One sure way for a smaller biotech company to gain investor attention has been to partner a drug candidate with a larger pharmaceutical or biotech company. Such partnerships were seen as providing validation for the drug candidate's quality, market potential and chances of success.

I believe the days of biotech requiring largecompany validation are over. Investors now realize that drug development is a game of

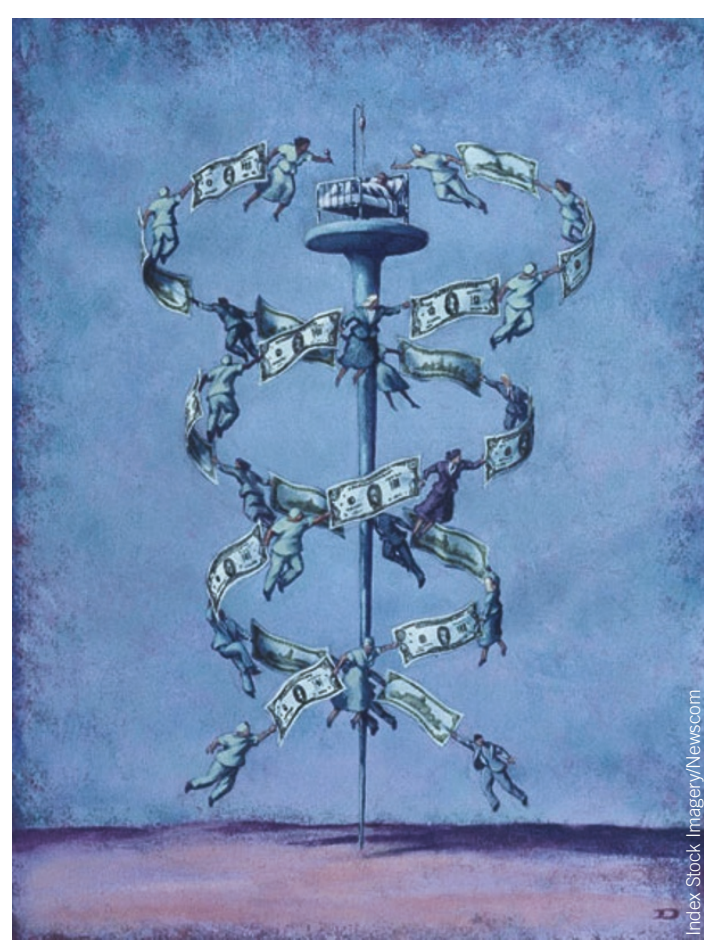


chance. Given the harsh reality that $90 \%$ of clinical-stage drug candidates ultimately fail to make it to the market (including $90 \%$ of those candidates developed by the larger companies themselves), it is silly to suggest that collaborative deals provide much validation.

In most cases, deals appear to be driven as much as anything by the economics of risk and reward. Many large biopharmaceutical companies are happy to make an option payment in the form of an upfront milestone to see how a drug candidate performs in subsequent trials. In the future, investors are likely to reward only companies who choose to out-license their compounds if the economics of a deal are attractive.

\section{Intellectual property}

Historically, it was a safe assumption that any biotech product was covered by solid intellectual property lasting well into the next decade. Each year, investors have become accustomed to pharmaceutical companies losing billions of dollars of sales to generics whereas biotech drugs have been sheltered from any such risk.

Over the next ten years, several small-molecule drugs marketed by the biotech industry will see their patents expire. In addition, it is highly likely that most major markets will create a route for the approval of follow-on biologics. Although protein-based drugs are unlikely to experience the same dramatic loss in value that savaged the commercial value of small molecules, the markets that innovative biotech products serve will gradually become more competitive.

Whereas biotech products are still likely to hold an advantage over traditional pharmaceuticals, in the future they will be forced to compete against ever-more innovative biotech products and convergent technologies like medical device-drug combinations, in some cases.

\section{Trade sales}

During an average year, the biotech industry features between two and four significant ( $>500$ million) acquisitions of smaller companies by larger ones. The perception has been that the combination of a small biotech company's innovative and emerging products with large company manufacturing and commercial capabilities creates a synergy that can be leveraged by all.

With the growing number of successful smaller companies and the need for larger companies to augment their growth, there is the perception that mergers might become more commonplace. We believe smaller companies with late-stage products will hold more leverage over potential acquirers. As a result, we think larger companies will be required to pay a higher price for such acquisitions.

To us, the innovative step in the biopharmaceutical business is drug discovery and development. Manufacturing, sales and marketing have become commodities that anyone with capital can access. In this environment, large companies can only offer small companies one thing: an attractive acquisition price. With the price to acquire a company likely going up, it will become more difficult for larger companies to rationalize an acquisition based on cost synergies alone as has been done so often in the past. In the future, investors will pay a premium for companies that appear to be capable of growing organically as opposed to through acquisition.

\section{Public offerings}

Biotech investors have grown accustomed to initial public offering (IPO) 'windows', which present themselves every two to three years. There is still a widely held perception that during such windows, the buyers of potential IPOs are quite indiscriminate and will purchase stock

Although all sectors of the stock market experience the ebb and flow of investor interest, US biotech investors are more sophisticated now and judge companies more on individual merit rather than on sector trends.

at reasonably high prices in almost any biotech company. To the extent that history supports this perception we will not likely see much irrational exuberance over biotech in the next ten years.

Investment banks typically advise private companies to pay close attention to when such IPO windows occur and run their IPO plans accordingly. As the biotech industry matures, the boom-and-bust cycles that the industry was known for in the past appear to be subsiding.

Although all sectors of the stock market experience the ebb and flow of investor interest, US biotech investors are more sophisticated now and judge companies more on individual merit rather than on sector trends. In the future, I believe that private companies will only contemplate an IPO when it is apparent that a company is mature enough to capture and maintain public interest.

\section{Product innovation}

Biotech products cost hundreds of millions to develop. Perhaps not surprisingly, they are becoming the most expensive medicines on the market. For much of its history, the biotech industry has successfully argued that biotech companies deserve a good return on this investment so that they can continue to reinvest in innovative new medicines that fetch a premium retail price. Likewise, legislators, patient groups and payors have generally rewarded biotech companies with carte blanche when it comes to reimbursement and pricing.

The industry has grown to the point where its products have become a significant burden on the healthcare system. In the future, it appears that products will require some form of cost-benefit justification. Only truly innovative products will avoid pricing pressures. Thus, the industry will need to focus more on innovative products that can recapture their investment. Investor experience with me-too pharmaceutical products highlights the pitfalls of backing such compounds.

\section{Management}

Biotech managers are often considered critical to the success of their companies. Many investors believe a good CEO can create significant shareholder value and that particularly capable executives are even able to reverse the prospects of a troubled company. Historically, the biotech industry has considered good CEOs to be in short supply and has handsomely rewarded executives with a successful track record.

Favorable compensation trends for biotech managers have been facilitated by a lack of stock option expensing and trends toward higher executive pay in other industries. In reality, it is very difficult for a biotech CEO to create value. Although the converse is not true (it is easy to destroy shareholder value through fraud, dishonesty or poor business dealings), perhaps the best a CEO can do is to create an environment that fosters success on the part of others.

Biotech is still an R\&D-driven enterprise and CEOs rarely determine whether or not a drug candidate succeeds. Those CEOs who are provided with enough successful drug candidates will look like geniuses at business, but might not deserve to be rewarded as such. Investors will likely pay more attention to management compensation in the future.

\section{Conclusions}

Biotech's striking success over the past decade has placed the industry on solid footing. Whereas biotech should continue to grow and prosper, matching the success of the past ten years will be a challenge and require successful execution on multiple fronts-and awareness that the financial community will increasingly be judging it with a different measuring stick. 


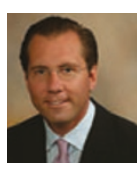

\section{The investment banker's view}

David J Strupp, Jr

As early-stage biotech companies mature into more developed organizations-focusing on later-stage trials or planning for a commercial launch-investment bankers play an increasingy important role in supporting their growth. Investment bankers provide a wide range of capital raising services, such as raising large private equity rounds, taking companies public, and managing follow-on equity offerings. Bankers also assist biotech companies with the review and execution of strategic options in the area of mergers and acquisitions (M\&A). In short, investment bankers can serve as nonpartisan strategic advisors to growing biotech companies, helping them reach the next stage in their development.

As the industry continues to mature, the valuation drivers over the next decade are likely to be very different from the ones that have taken the industry to where it is today. Increasingly, the drivers of value will be shaped by two fundamental changes in the biotech industry: first, an enhanced focus on building commercially oriented organizations that are focused on earnings growth; and second, a change in the manner in which investors and management teams measure and define success.

Earnings growth drives stock price-or does it when it comes to the biotech industry? Unlike most industries, the historical drivers of valuation for biotech companies have been 'story' related, such as research and development news, US Food and Drug Administration (Rockville, MD) milestones and partnership announcements with large pharmaceutical companies.

In fact, fewer than 20 biotechs have reached profitability based on product sales. As the industry matures and more companies gain profitability, investors will begin to evaluate the industry using more traditional metrics. Although the industry will always have a thriving contingent of small companies whose products or technologies are still in the $R \& D$ stage, the vast majority of the value in the industry resides in those companies that have reached profitability.

Suprisingly, the handful of profitable biotech companies represents more than $80 \%$ of the value of the overall industry. These profitable companies represent only a small

David J. Strupp, Jr. is Partner, Head of Health Care Investment Banking at ThinkEquity Partners LLC.e-mail:dstrupp@thinkequity.com profitability. fraction of the total number of companies in the industry. Therefore, much of the future growth of the biotech industry will come from those companies that cross over to sustained

\section{Tough crowd}

If the rest of the industry is to mature beyond the point of essentially being the research arm of the pharmaceutical industry, companies will be required to adopt a more commercially oriented approach to drug development and recruit professional management teams that are focused on the bottom line.

Most of the biotech industry continues to operate as $\mathrm{R} \& \mathrm{D}$ organizations that are more focused on future product development than the bottom line. The result is that the industry has produced little in the way of sales. And those companies that have produced sales do a poor job turning those sales into profits. In

The economics of

independence and the requirement for numerous rounds of equity financing need to be compared with

\section{a successful sale to a larger biotech company or large pharmaceutical company.}

fact, in 2004, the five largest revenue-generating, but unprofitable, biotech companies achieved an aggregate of over $\$ 830$ million in revenues but spent over $\$ 950$ million on $\mathrm{R} \& \mathrm{D}$. Companies that operate in this manner have seen a significant depreciation in thier market valuation. Although these companies have a respectable average market capitalization of $\sim 2.3$ billion, they have lost on average $\$ 4$ billion of market value over the past five years, which adds up to an aggregate loss of value of over $\$ 23$ billion.

Contrast this with the five largest, but profitable, biotech companies that have average market capitalizations of $\sim \$ 46$ billion and have gained an aggregate of $\$ 91$ billion of value.

\section{What passes for success}

Another factor that will have an important impact on value creation in the biotech industry will be an expected change in how 'success' is defined by the industry's investors, boards and management teams. In the broadest sense, success for a biotech company has been defined by a path that begins with backing by blue-chip venture capitalists. It then progresses to a corporate partnership, an IPO and then perhaps the launch of a commercial product.

Success has been typically defined by the ability to maintain independence as a publicly traded company. In this sense, it is interesting to compare the biotech industry to the medical device industry. Unlike in the biotech industry, in the medical device industry a successful exit is defined as a sale to one of the large-cap companies. Although there are many notable exceptions, the sale of a biotech company has most often been associated with failure, not success. This is changing.

As the biotech industry continues to mature, the manner in which companies are funded and the approach to M\&A will likely change. The economics of independence and the requirement for numerous rounds of equity financing need to be compared with a successful sale to a larger biotech company or large pharmaceutical company. Independence alone cannot define success if it requires numerous rounds of private and public equity financings. The companies that will be able to make a model of independence work will be those that are able to establish business models that allow the achievement of key value-driving milestones using less capital. Similarly, an M\&A exit will likely become more common and both the investors and management teams should begin to define success by the sale of their company.

\section{When in Rome}

The aggregate value of the biotech industry is dominated by a handful of companies. Although the industry has over 4,400 companies, the ten largest companies represent over $80 \%$ of the value. Therefore, the most important determinants of the overall value of the industry will be those factors that influence the top-tier companies. With Amgen and Genetech having traded at valuations in early 2006 that have approached $\$ 100$ billion in market capitalization, they have surpassed the market caps of many of the large pharmaceutical companies and are both now within the top ten pharmaceutical companies in the world by market capitalization.

A key question for the industry will be at what point should we be judging the top-tier biotechs using the same metrics we use to judge large-cap pharma, and at what point will biotechs start behaving like pharma? Arguably, from a valuation perspective, Amgen is already 
judged as if it were a pharma company and is, in fact, already behaving as such. At the end of 2001, Amgen traded at a profit/earnings (P/E) ratio of $\sim 41 \times$. This compares to a current $\mathrm{P} / \mathrm{E}$ ratio of only $21 \times$. This multiple compression took place during a period of time when the average $\mathrm{P} / \mathrm{E}$ ratio for biotech companies has remained somewhat constant. In fact, the current average $\mathrm{P} / \mathrm{E}$ ratio for the top ten biotech companies is $\sim 37 \times$. Arguably, Amgen's current $\mathrm{P} / \mathrm{E}$ of $21 \times$ is more comparable to the average pharma $\mathrm{P} / \mathrm{E}$ of $\sim 16 \times$.

In a maturing industry where multiples are still high, companies should turn to M\&A to take advantage of their valuable currency. Amgen has been the most aggressive shopper over the past few years, having acquired Immunex (Seattle, WA) and Tularik (S. San
Francisco, CA), with a pending acquisition of Abgenix (Fremont, CA). Other top-tier biotech companies should begin to turn to M\&A for future growth, too.

Predictions have been made over the past several years that M\&A is necessary to consolidate the biotech industry, which is populated by too many companies lacking critical mass. I would argue that this fragmentation will continue to exist and will remain one of the fundamental characteristics of the biotech industry. Nonetheless, the industry should see a marked increase in M\&A activity that is driven by the top-tier companies seeking future growth opportunities much the way the pharmaceutical companies have sought growth through acquisition. These acquisitions will likely be larger in size.

\section{Conclusions}

Over the past 30 years, the biotech industry has proven its ability to produce innovative products and technologies that have outpaced the pharmaceutical industry. The key for the next decade will be for the biotech industry to maintain this level of innovation while adopting an enhanced commercial orientation.

The academic culture and high-risk tolerance of the biotech industry have been key value-drivers since inception, but science alone cannot drive the future value of the industry. The successful biotech companies will be those that continue to harness the attributes of innovation while focusing the organization on commercial goals that drive earnings growth. 